\title{
An Overall Urban System: Integrating Central Place Theory and Urban Network Idea in the Greater Pearl River Delta of China
}

\author{
Yongzhong Guo \\ Nanjing Agricultural University, Nanjing, China \\ Email: simonyzg@hotmail.com
}

How to cite this paper: Guo, Y.Z. (2018) An Overall Urban System: Integrating Central Place Theory and Urban Network Idea in the Greater Pearl River Delta of China. Journal of Environmental Protection, 9, 1205-1220.

https://doi.org/10.4236/jep.2018.912076

Received: October 1, 2018

Accepted: November 4, 2018

Published: November 7, 2018

Copyright $\odot 2018$ by author and Scientific Research Publishing Inc. This work is licensed under the Creative Commons Attribution International License (CC BY 4.0).

http://creativecommons.org/licenses/by/4.0/

\begin{abstract}
Following a half century of popularity, central place theory experienced 20 years of neglect when the new urban system theory of network modeling gained attention at the beginning of the 1990s. However, central place theory remains valid, and it seems there has been a reemergence with it. Using the Greater Pearl River Delta (Greater PRD) as an experimental study region, this paper intends to present an empirical study that validates central place theory and shows that it can be integrated into an overall regional urban system. The study uses the compound Central Place Importance (CPI) to evaluate whether there is a hierarchy among the urban centers within the study area. The results indicate the existence of a hierarchy. Furthermore, empirical observation finds distinct complementarity relationships, rank-size distributions, and co-operative actions between the different cities, thus substantiating the claim that central place theory can be incorporated into an overall regional urban system. Besides, the presence of the densely distributed modern infrastructure system also appears to constitute a dimension of the overall urban system. There need further theoretical and empirical studies in order to support this proposition.
\end{abstract}

\section{Keywords}

Central Place Theory, Network Urban System, Overall Urban System, Central Place Importance, Complementarity, Rank-Size Distribution, Co-Operation,

Greater Pearl River Delta

\section{Introduction}

Urban systems studies have evolved for almost two centuries since von Thunen 
published the famous book Der isolierte Staat in 1826. Important contributions have been made in many disciplines. Although the urban network idea seems becoming popular due to advanced technologies and economic globalization, traditional theories such as central place theory (CPT) still work and even have signs of reemergence.

Compared to many scholars who assert that central place theory have outdated and have been supersede by theories such as new economic geography in explaining the spatial structure and intercity relationships of urban systems, a few researchers claimed that CPT still have merits, and can be part of the modern complicated urban system paradigm. Parr stated that the urban system of a region comprises two distinct components: activities governed by central place theory principles and activities influenced by specialized-functions, both helping to form the overall urban system together [1]. Meijers believed that there should be a sequential link between CPT and urban network model [2].

The purpose of this paper is to demonstrate that central place theory not only works, but also can be integrated with the emerging urban network idea. This will be achieved through the concept of overall urban system, and through the definition and implementation of a synthesized index of Central Place Importance (CPI), which will use the Greater Pearl River Delta as an empirical study area.

\section{Theoretical Fundamentals}

\subsection{From Central Place to Network Urban System}

Originally formulated by Walter Christaller [3] and thereafter developed by August Lösch [4], central place theory (CPT) provides an explanation for the number, size, spacing, location and functional content of settlements within a sub-national or regional area.

Since the pioneering formulations of Christaller and Lösch, the central place model has been elaborated, extended and criticized by many researchers. The major elaborations have essentially involved relaxing the restrictive assumptions upon which central place theory was based.

Central place theory's inability to accommodate the processes of change and its anachronistic assumptions has been identified as significant shortcomings [5]. CPT has also been challenged because of its somewhat weak explanation for the emergence of the hierarchy and its lack of a solid microeconomic foundation [6]. Furthermore, even when extended, the central place model is unable to address the location of economic activities that are not market-oriented and therefore not governed by principles of centrality.

Despite the many endeavors and accomplishments of numerous researchers, the basic theoretical principles behind the theory remain, although it has encountered increasing obstacles over time. However, these deficiencies do not require the abandonment of central place theory but rather indicate the need for a broader framework that can subsume the central place model [7]. 
The network urban system model appeared during the last decade of the $20^{\text {th }}$ century, although its basic principles can be traced back to the concept of the "dispersed city" [8]. Camagni and Salone [9] defined "city networks" as systems of horizontal, non-hierarchical relationships among specialized centers that provide externalities from complementarity or from co-operation among centers. Kloosterman and Musterd [10] described "polycentric urban regions" as collections of historically distinct, administratively and politically independent cities that are located in close proximity to one another and that are well connected through infrastructure. Obviously, this urban network theory has at least two features that better describe the spatial distribution and arrangement of urban economic activities: complementarity, different urban centers fulfill different and mutually beneficial roles; and co-operation between different settlements.

\subsection{A View of the Overall Urban System}

\subsubsection{Some Missing Elements}

As originally defined by Christaller, the concept of centrality, wherein economic activities essentially include retail and/or service industries, is still valid. However, activities exist that contribute to urbanization and therefore help to mold an urban system but do not figure in the central place framework. Here, these activities are referred to as "specialized-function activities". Functions relating to tourism, civil administration, public facilities, or military installations can form a basis for urbanization. In the case of resource exploitation, the existence of a resource does not guarantee its exploitation or the associated urbanization. Another important specialized-function activity is manufacturing. Manufacturing activity tends to be influenced by a variety of factors other than centrality. Firm agglomeration is another example in which the central place model does not play a role in locational choice and thereby influence urbanization because here, the dominating driving forces are agglomeration economies.

\subsubsection{The Overall Urban System}

The idea of overall urban system was formally put forward by John B. Parr in 2002 [7]. Except for combining CPT principles and specialized-functions, this overall urban system should have several distinctive features.

The first characteristic is related to the nature of the hierarchy of centers. In a central place system, the hierarchy is successively inclusive, whereas in an overall urban system, the functional hierarchy is most likely more complicated and generally includes both central place activities and specialized-function activities".

The next characteristic is concerned with the socio-economic structure of the urban centers and how it varies with size. Two dimensions must be discussed. One concerns the degree of diversification or complexity represented by the various functions within an urban center. It is generally accepted that the larger the center is, the higher its level of diversification or complexity. This characteristic is very strong with respect to the central place component of the urban system, but it is also valid for the specialized-function component. 
Another aspect of the socio-economic structure of urban centers concerns the extent of differences between the profiles among the different settlements within an entire urban system, each settlement's socio-economic structure, and the differences between (or distances to) other settlements. This aspect can be labeled "complementarity".

One further characteristic of this broader urban system concerns the size distribution of urban centers. Generally, the size distribution of urban centers conforms to the commonly known "rank-size distribution" formula, which can be expressed as follows:

$$
\log P_{R}=\log P_{1}-q(\log R)
$$

where $P_{R}$ is the size (population) of an urban center of rank $R$, and $P_{1}$ is the size of the largest urban center, while $q$ is the slope of the function representing the extent of the center-size inequity or the level of interurban concentration.

In fact, with respect to the size distribution of urban centers, another important aspect should be noted: the spatial distribution of urban centers across a region's geographic territory. Should they be evenly distributed or unevenly distributed? To what extent? There appears to be an extremely wide variety of territorial distributions of urban centers across different regions around the world.

Based on the previous discussion, it appears that the central place theory approach is wanting in a sufficiently large number of aspects, and it cannot be regarded as a general theory of the urban system. However, rather than replacing the central place model with the network model, it is widely accepted that a sequential link between the models exists, and path-breaking studies can be conducted not only to create a new theoretical paradigm but also to examine empirical case studies. Central place theory might provide a foundation upon which other facets (e.g., specialized-function activities) of the urban system can be superimposed.

Here, an overall urban system concept is formulated based on the idea that the urban system of a nation or region comprises two quite distinct components. The first is concerned with the range of economic activity; the locational pattern for this activity is governed by the principle of centrality and can be approached in terms of central place theory. The second component involves specialized-function activities, whose locational pattern results from a diverse set of influences. Together, the two components help to form an overall urban system [7]. Thus, features of the network model and characteristics of the central place model are present within this overall urban system.

In the following sections, empirical data from the Greater Pearl River Delta are presented and tested to verify the idea that the central place model and the network model can be integrated and that these two dimensions can form an overall urban system.

\section{The Greater Pearl River Delta Study Area and Data}

Facing the South China Sea to the south and located in a central position in 
coastal southern China, the Greater PRD study area is a relatively isolated region, with the Changsha metropolitan area $700 \mathrm{~km}$ to the north, the Xiamen metropolis $500 \mathrm{~km}$ to the east, and the city of Nanning $800 \mathrm{~km}$ to the west. The geographic range of this study area is between 21.6 and 24 degrees north latitude and 112 and 115.4 degrees east longitude. The area is $44,891.2 \mathrm{~km}^{2}$ and had a population of $61,861,000$ in 2010. Administratively, the Greater PRD consists of eleven prefecture-level and upper administrative/political units: two sub-provincial level cities, namely Guangzhou, and Shenzhen; seven prefecture-level cities, namely Huizhou, Dongguan, Zhuhai, Zhongshan, Jiangmen, Foshan, and part of Zhaoqing; and two Special Administrative Regions (SARs, considered provincial level political units), namely Hong Kong and Macao (Figure 1).

This study area's natural endowments appear to be almost perfect, although there are few mineral deposits, such as oil and iron, for traditional industries. The loamy land, comfortable weather, abundant surface water, and long history of farming culture have made the Lower Pearl River Basin a productive region. Agriculture flourished in the past, and Guangzhou (the capital of Guangdong province) was always considered to be the most important commercial and cultural center in southern China. Since 1978, with the adoption of China's policy of openness and reform, the Greater PRD has become a center of rapid economic growth and systemic reforms, a key destination for foreign investment, and a platform for China's growing integration into the global economy. Within the mainland portion of the Greater PRD (except Hong Kong and Macao), per capita GDP grew at 17.9 percent annually between 1978 and 2000 and 13.4 percent annually from 2000 to 2008. Contributions from primary, secondary and tertiary activities in the area changed dramatically during the past three decades, from $25.8 \%, 45.3 \%$, and $28.9 \%$ in 1980 to $2.4 \%, 50.3 \%$, and $47.3 \%$, respectively, in 2008 .
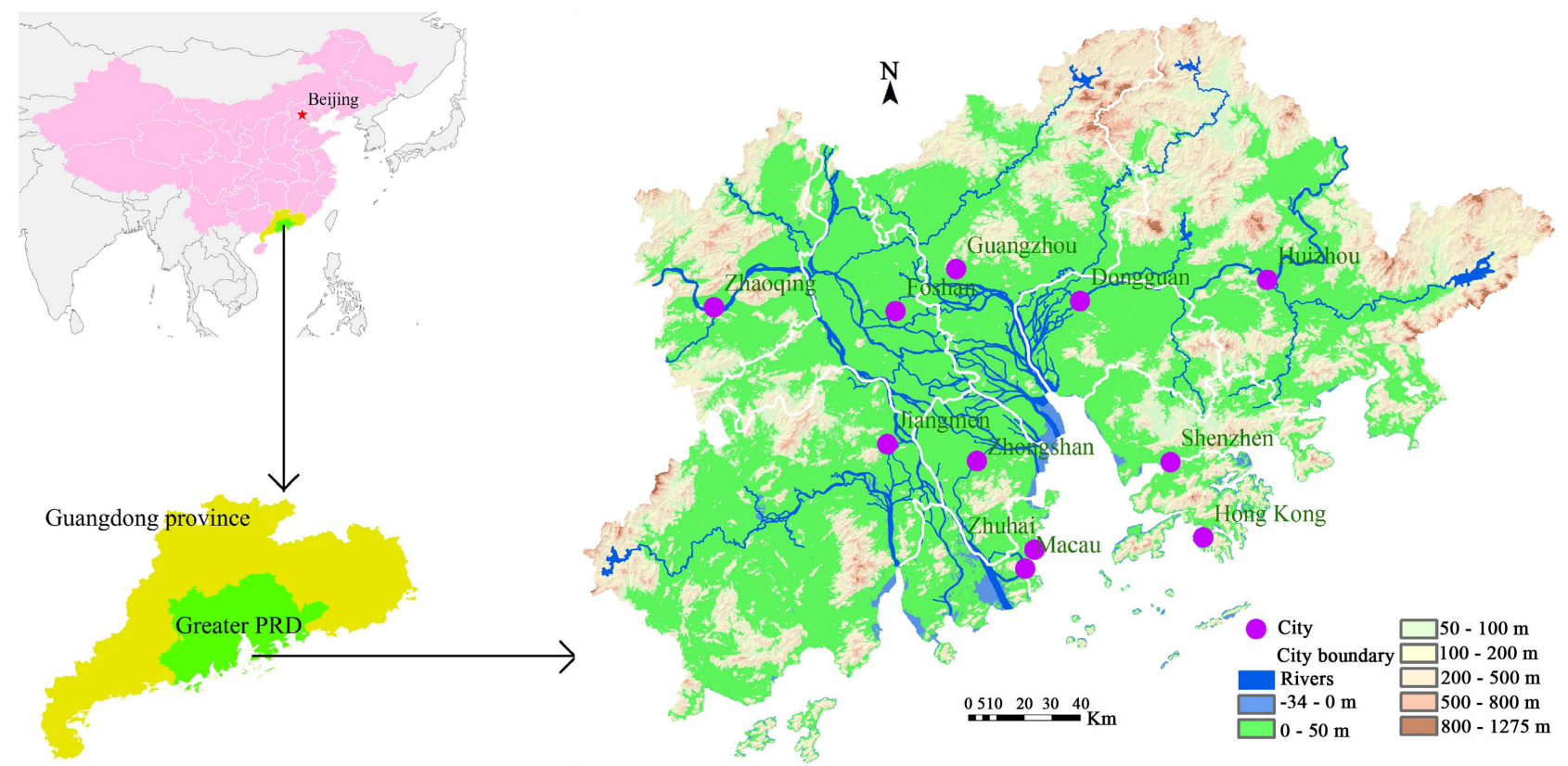

Figure 1. Location and physical geography of the Greater PRD study area. 


\section{Methods}

\subsection{Definition of the Network Urban System}

In central place theory, an urban system consists of a hierarchical ranking of urban centers, associated market areas and transportation networks. A polycentric urban region can more or less be identified by structural characteristics such as the location of cities relative to each other and their size distribution. Urban networks could be considered to be an advanced type of polycentric urban region. There must be a certain level of functional integration and complementarity for a regional urban system to be justified as an urban network.

A network urban system (overall urban system) can be defined as a nodal region that consists of nodes (cities, towns, firms, etc.), linkages between the nodes (infrastructure, ties), socio-economic complementarity relationships, interactions (flows) between the centers, and areas surrounding the nodes (hinterlands, including farmlands, ecological/environmental protection areas, etc.). Hierarchical relationships may exist between the urban centers (nodes), while complementarity relationships and spatial interactions between the urban centers must be present, at least to some extent [2] [9] [11].

The scale of a network urban system can be as small as the Randstad (less than $10,000 \mathrm{~km}^{2}$ ), or as large as the Yangtze River Delta (more than 100,000 $\mathrm{km}^{2}$ ). The distances between the urban centers range from dozens of kilometers to a little more than 100 kilometers. Nevertheless, the keys are the polycentric urban structure and the complex intercity relationships.

\subsection{Centrality, Nodality, or Central Place Importance?}

When considering a regional urban system, one of the most important issues is the definition and measurement of the urban center's importance within that urban system. The cornerstone of Christaller's approach is his concept of a central place. A central place is a place that provides goods and services for consumers in the surrounding area (hinterland) in addition to supplying its own inhabitants. Traditionally, in the Christallerian central place theory, there is a strict distinction between centrality and nodality. The following formula explicitly expresses these two concepts and the difference between them:

$$
C=N-L
$$

where

$C=$ the surplus of importance, i.e., the relative importance of a place or its centrality;

$N=$ the importance of a place plus its complementary region, i.e., the absolute importance or nodality; and

$L=$ the importance of a settlement as a unit in consuming central goods and services or in local consumption.

Strictly speaking, Christaller's original intention was to define and measure centrality when considering a central place and the entire regional urban system. 
However, after having been studied, extended and even empirically verified over many years, fundamental weaknesses of central place theory have appeared. Researchers failed to operationalize a pivotal concept of centrality consistent with Christaller's original definitions. This inability led to the use of proxy measures for centrality and to its confusion with nodality [12]. In addition, with the development of urban systems research during the 1950s and 1960s, the explicit distinction between centrality and nodality was gradually lost. Moreover, with respect to network urban systems, nodality theoretically replaced centrality as the measurement proxy for the relative importance of an urban center.

It does not appear to be absolutely necessary to use the strictly defined centrality concept to implement a regional central place system. Using an integrated concept based on datasets including GDP and other socio-economic statistics appears to yield more realistic results and is not extremely difficult. Nevertheless, a central place plays the central place role regardless of the traditional difference between centrality and nodality; this means that the concept of the central place can be more broadly applied to include other socio-economic aspects in addition to retail and service industries, such as tertiary activities (tourism, public facilities, civil administration), resource exploitation, manufacturing, etc. An agglomeration can serve as a central place.

Here, a comprehensive index, namely the central place importance (CPI), is employed as a proxy to define a central place, then a regional central place system, and there after a network urban system. The CPI may include values for total population, GDP, company headquarters, government administration location, transportation intersection, etc., as shown by the following formula:

$$
\mathrm{CPI}=\sum F_{i} * W_{i}
$$

where CPI is the central place importance, $F_{i}$ is the value of an influence factor's central place importance (e.g., GDP, total population...), and $W_{i}$ is the weight of that corresponding factor, $i=1,2, \cdots, n$.

\subsection{Ranking the Central Places within the Greater PRD}

Based on the criteria for choosing central place importance factors described by [13], objective, comparable and incorporable, five factors were employed as contributors to the CPI. The formula is as follows:

$$
\mathrm{CPI}=P+D+G+C+(A+S+R+H) / 4
$$

where CPI is the value of the compound Central Place Importance, $P$ is the value of the total population of the settlement, $D$ is the value of the GDP, $G$ is the value of the government administration location, $C$ is the value of the company headquarters location, and $A, S, R$, and $H$ are values for the airport, harbor, railways entering the central place, and highways entering the central place, respectively. The four transportation sub-factors $(A, S, R$, and $H$ ) were divided by 4 in order to make the importance of the transportation factor equal to the other four factors $(P, D, G$, and $C)$. Each of the five factors is assigned the same weight 
for convenience, but this weight can be adjusted to reflect better situations in future studies.

For reasons of choosing these five factors, maybe the following can provide some explanations: Generally, the volumes of population or GDP often represent economy sizes that in turn indicate the settlements' significance. With regard to the importance of transportation factor, values of airport and harbor are decided by annual traffic volumes, while values of railway and highway importance are measured by number of rays entering the target settlement [14]. Considering the modern complex economy system which usually controlled by advanced service industries and governmental interventions, the factors of government administration location and the company headquarters location were chosen, and the former was decided by level of government while the later measured by annual productivities.

The study region was demarcated into $\mathbf{3 2 0}$ incorporated sub-regions, with the larger metropolitan sub-regions restricted to continuous built-up areas around the downtown. Areas far away from the city centers were defined as independent urban centers. Examples include Baoan and Xixiang districts (15 kilometers from the city center of Shenzhen city) and Huadu and Panyu (25 kilometers from the city center of Guangzhou city). The smallest urban centers are on the islands located in the South China Sea near the mouth of the Pearl River, with a collective population of a little more than one thousand.

All of the corresponding factors' statistical data were normalized into values from 0 to 100 . Value 0 is the lowest value within the study area, while value 100 represents the highest value. Most of the statistical data are objective records derived from statistical agencies and internet sources except for the values of government locations, which were assigned subjectively. Company headquarters location values were calculated according to their business volume. For convenience, different types of highways (expressways, national highways, and provincial highways) were treated as the same class, and railways and high-speed railways were considered to be the same. Some final CPIs are shown in Table 1.

\subsection{Grouping and Classifying the Central Places}

There are two fundamental premises when considering a central place system: the measurement of the importance of the central place, which was discussed above, and the hierarchical arrangement of central places and the methodology for grouping and classifying the centers. By using some compound indice (e.g., the Central Place Importance), it is possible to evaluate and classify the urban centers into groups and thereafter analyze other urban system features, such as the different socioeconomic activities (complementarity) and rank-size distributions.

Clark [15] proposed a widely accepted definition of the concept of a group: A group is a collection of points in which every individual is closer to some member of the collection than to any individual outside of the collection. Furthermore, the concept of a group is hierarchical, whereby large groups contain 
Table 1. Some of the central place importance values and the ranking and classification results within the greater $\mathrm{PRD}$.

\begin{tabular}{|c|c|c|c|}
\hline Central Place Name & CPI & Rank & Class \\
\hline Hong Kong (HK) & 1795.03 & 1 & 6 \\
\hline Guangzhou Metropolis (GZ) & 1369.74 & 2 & 6 \\
\hline Shenzhen Metropolis (SZ) & 1154.7 & 3 & 6 \\
\hline Macao (MC) & 493.27 & 4 & 5 \\
\hline Foshan Metropolis (FS) & 344.5 & 5 & 5 \\
\hline Zhuhai Metropolis (ZH) & 339.69 & 6 & 5 \\
\hline Jiangmen Metropolis (JM) & 248.19 & 7 & 4 \\
\hline Zhongshan Metropolis (ZS) & 237.06 & 8 & 4 \\
\hline Dongguan Metropolis (DG) & 218.01 & 9 & 4 \\
\hline Zhaoqing Metropolis (ZQ) & 173.64 & 10 & 4 \\
\hline Huizhou Metropolis (HZ) & 170.6 & 11 & 4 \\
\hline Xinan (XA) & 137.77 & 12 & 3 \\
\hline Humen (HA) & 128.15 & 13 & 3 \\
\hline Panyu (PY) & 110.43 & 14 & 3 \\
\hline Shunde (SD) & 107.66 & 15 & 3 \\
\hline Huadu (HD) & 103.85 & 16 & 3 \\
\hline Sanshui & 93.71 & 17 & 2 \\
\hline Changping & 91.07 & 18 & 2 \\
\hline Lundun & 51.26 & 49 & 2 \\
\hline Xiqiao & 51.12 & 50 & 2 \\
\hline Dalingshan & 49.68 & 51 & 1 \\
\hline Leliu & 48.92 & 52 & 1 \\
\hline Guishan & 4.16 & 318 & 1 \\
\hline Wanshan & 4.12 & 319 & 1 \\
\hline Dangan & 4.12 & 320 & 1 \\
\hline
\end{tabular}

smaller groups within them. Because the compound values of the Central Place Importance were already calculated, using this definition of group, and by measuring the distances between the values, all the 320 settlements were divided into six groups. Accordingly, six classes, classes 1, 2, 3, 4, 5, and 6, were assigned to the settlements, with class 6 as the top class while class 1 as the smallest.

\subsection{Complementarity Analysis}

The idea of complementarity is not only a primary feature of the network model compared with the traditional central place model, it is also an important characteristic of the overall urban system. By using the correspondence analysis 
technique on the Greater PRD study area, empirical data indicate that complementary relationships with regard to socioeconomic roles indeed exist between the urban centers.

Correspondence analysis is a technique that is used to analyze the association between the rows and columns of a table or matrix by representing the rows and columns as points in a low-dimensional Euclidean space. Categories with similar distributions are represented as points that are close in space, and categories that have very dissimilar distributions are positioned far apart [16]. Total inertia is an important measure that describes the extent of differentiation in the socio-economic profiles of a group of urban centers. The centroid represents the average profile. The greater the distances of the category points from the centroid, the higher the inertia is. The highest attainable inertia is equal to the dimensionality of the problem (the number of urban centers-1), while the lowest is zero. Another interesting statistic was defined by Meijers [16]: the complementarity ratio. The complementarity ratio is calculated by normalizing the total inertia by dividing it by the maximum total inertia possible and multiplying the result by 100, which yields a value between 0 and 100 .

Within the Greater PRD, 11cities (2 sub-provincial level cities, 7 prefecture-level cities and 2 Special Administrative Regions) and 20 socio-economic elements from years 2004 and 2010 were analyzed. Using the Correspondence Analysis tool in SPSS 20, differentiation of socio-economic activities between the 11 cities, and the total inertia and complementarity ratio of the Greater PRD were calculated.

\subsection{Rank-Size Distribution Analysis}

The rank-size distribution provides information on the hierarchy of the centers and is therefore a good measure of the degree of monocentricity or polycentricity. However, for a region (or a network urban system) to be considered polycentric, two preconditions must be present: the slope of the regression line of the rank-size distribution must be flat, indicating that the urban centers are relatively equally sized, and the urban centers must be evenly distributed across the region's territory.

With regard to this study area, 13 largest metropolitan areas (with permanent population as criterion) were chosen as deputies to present the rank-size distribution in 2000 and 2010, respectively. By employing the SPSS 20 Graphs tool, the rank-size distributions were computed out.

\section{Results}

\subsection{Ranks, Groups and Classes}

As shown in Table 1, the CPI values of the 320 settlements range from 1795.03 (the largest) down to 4.12 (the lowest). Accordingly, the largest settlement ranks 1, while the smallest ranks 320. For classification, 3 large metropolises: Hong Kong, Guangzhou and Shenzhen, belong to class six (the top class). The rest set- 
tlements are: 3 to class five; 5 to class four; 5 to class three; 37 to class 2; and 270 to class one (the lowest class).

Figure 2 shows the rank size distribution of the top 60 settlements, and Figure 3 demonstrates the geographic distribution of the 320 settlements across the study area.

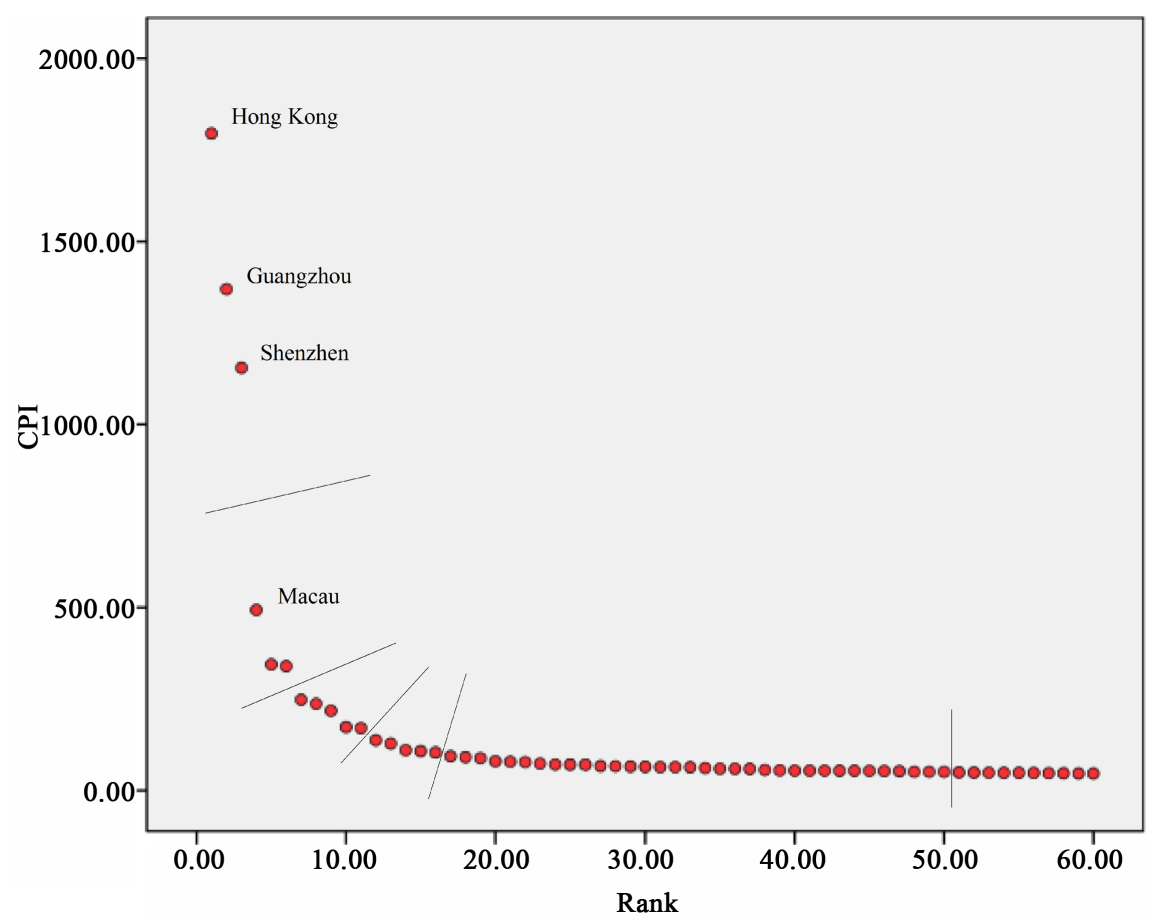

Figure 2. Scatter plot of the top 60 settlements' CPI values within the study area.

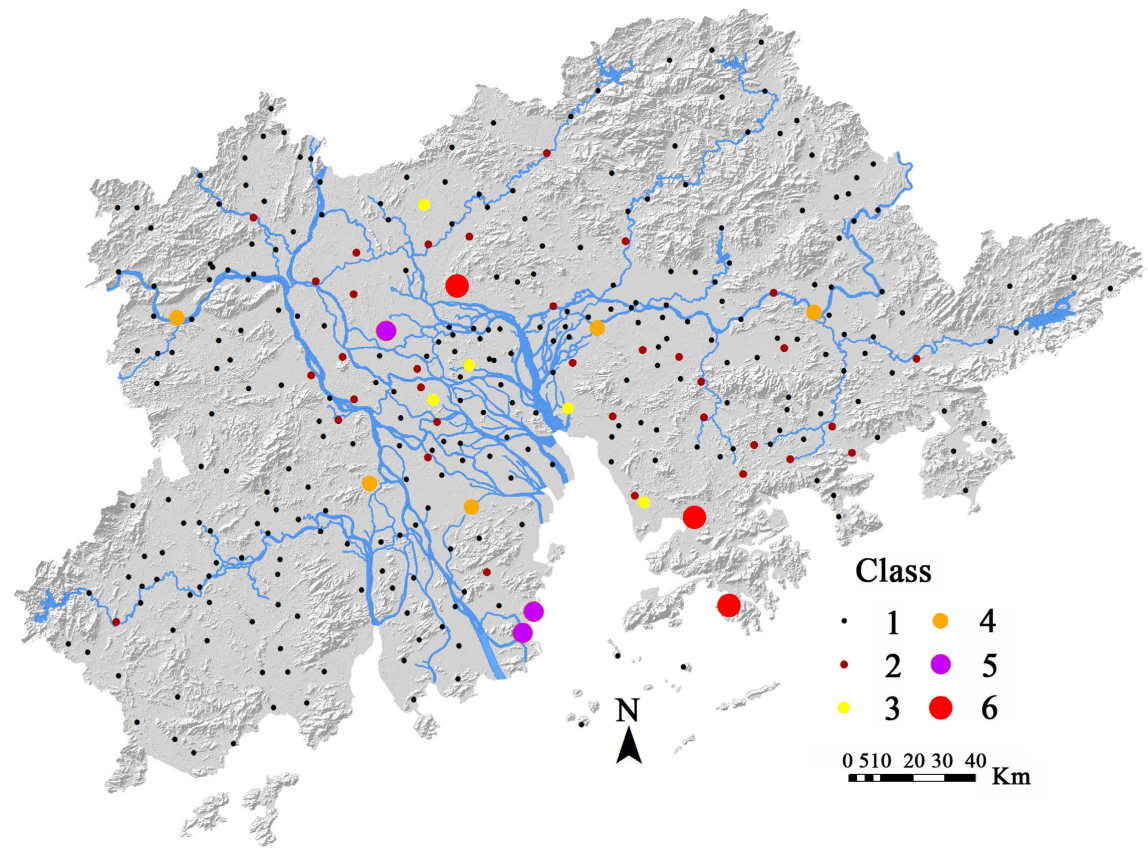

Figure 3. Distribution of the classified settlements across the Greater PRD study area. 


\subsection{Complementarity}

Table 2 indicates the results of the analysis for total inertia, the complementary ratio and the trend. It is obvious that there are differentiations in the socio-economic activities of the cities within the study area.

Compared with the Randstad, the differentiation level of the Greater PRD looks somewhat higher: the complementarity ratio for the Greater PRD is 8.3 7.5 (2004-2010), while for the Randstad, the corresponding value is 4.2 - 3.8 (1996-2002). However, both regions were becoming less differentiated (trend: $-9 \%$ and $-9.5 \%$, respectively), indicating the decreasing complementarity of economic and service activities.

These correspondence analysis results also graphically reveal the economic and service profiles of each city and the associations between the cities within the Greater PRD (Figure 4). It is evident that differentiations were indeed present. In examining Figure 4, several consequences can be identified. The eleven cities can be included in five groups given their roles as economic and service centers. In both 2004 and 2010, Macau was dominated by the gaming industry. Hong Kongacted as the leading city in the area and held a dominant position in commercial services and public services, air traffic and water transport. Three cities, Huizhou, Jiangmen and Zhaoqing, showed significance in agriculture. The other three cities, Foshan, Zhongshan and Dongguan, were all dominant in manufacturing industries. Finally, Guangzhou, Shenzhen and Zhuhai,
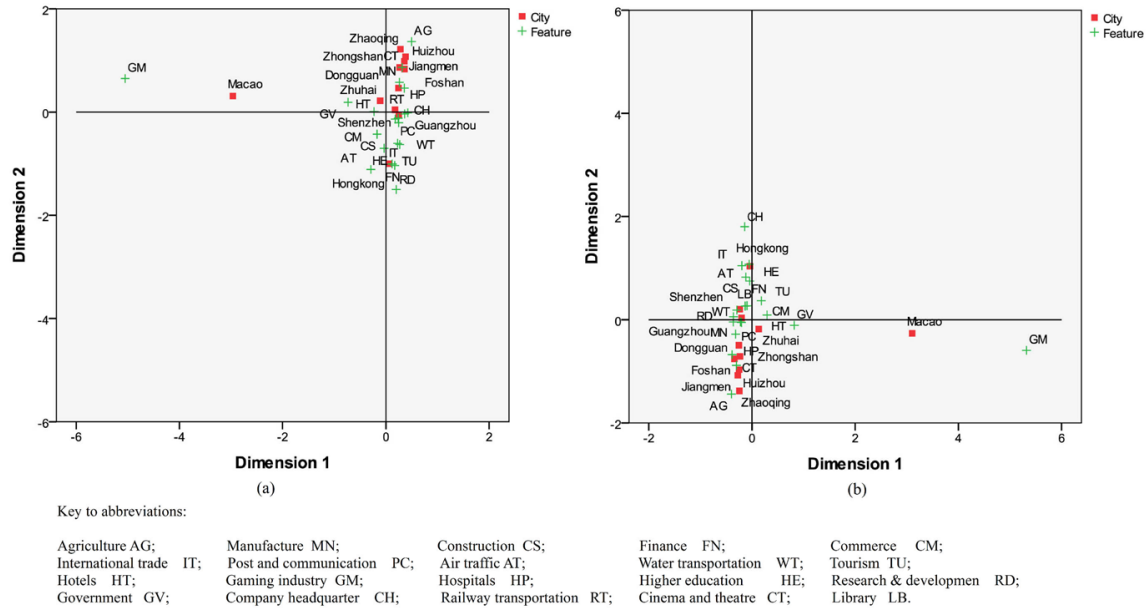

(b)

Figure 4. Differentiation in the spread of socio-economic activities over the 11 cities within the greater PRD study area, (a) 2004; (b) 2010.

Table 2. Correspondence analysis results in the Greater PRD compared with the Randstad.

\begin{tabular}{|c|c|c|c|c|c|}
\hline Region & \multicolumn{2}{|c|}{ Total inertia } & \multicolumn{2}{|c|}{ Complementarity ratio } & Trend (percentage change) \\
\hline Grand Pearl River Delta & 2004 & 2010 & 2004 & 2010 & \\
\hline$(\mathrm{N}=11)$ & 0.828 & 0.753 & 8.3 & 7.5 & $-9 \%$ \\
\hline Randstad & 1996 & 2002 & 1996 & 2002 & \\
\hline$(\mathrm{N}=14)$ & 0.545 & 0.493 & 4.2 & 3.8 & $-9.5 \%$ \\
\hline
\end{tabular}


which are more or less located close to the centroid origin $(0,0)$ of the graphs, should show profiles that are close to the average for the 11 cities. However, there were some differences between these last three cities. Guangzhouis the seat of the Guangdong provincial government and was the nearest to the centroid of the graphs representing the most average profile, while showed dominance in hospital care, higher education and railway transportation. Shenzhen, in addition to dominance in transportation, specialized in research \& development, finance, and international trade. The city of Zhuhai mainly specialized in manufacturing but also had an important transportation system.

\subsection{Rank-Size Distribution}

As revealed in Figure 5, the slope of the regression line of the 13 largest metropolitan areas was much steeper than the commonly compared Randstad, but not too steep. Moreover, the slope was becoming flatter during the last decade, indicating that the Greater PRD area was moving toward polycentricity. The coefficient of the slope of the regression line changed from -1.383 in 2000 to -1.104 in 2010. It appears that the slope of the regression line will further flatten instead of becoming steeper in the future, which means that the rank-size distribution of the Greater PRD will continue to become more polycentric. The explanation for this result is that many of the prefecture-level cities are growing faster than the top cities such as Hong Kong and Guangzhou. Besides, the geographic distribution of the 13 large metropolitan areas shows a relative dispersed pattern instead of concentrated.

\subsection{The Greater PRD Network Urban System (Overall Urban System)}

Although the intercity co-operation was not addressed within the above analysis, that indeed is one essential component of the urban network system. For the Greater PRD, this actually already exists, and will continue to develop. Examples include the Pearl River Delta Urban Cluster Cooperative Development Plan (2004-2020) adopted by Guangdong provincial government in 2005; the Outline
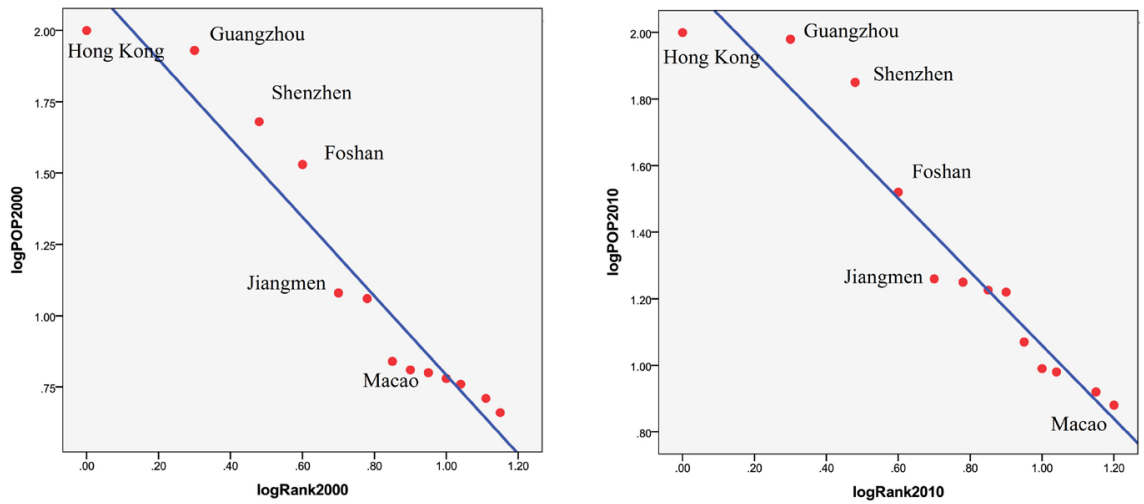

Figure 5. Rank-size distribution of 13 largest settlements within the Greater PRD study area. Slope regression line: $2000:-1.383 ; 2010:-1.104$. 
of the Plan for the Reform and Development of the Pearl River Delta (2008-2020) released by the national Development and Reform Commission in 2008; and the project of Hong Kong-Zhuhai-Macau Bridge (HZMB) to build a bridge linking the eastern and western wings of the PRD.

In conclusion, there are at least five dimensions demonstrating that a network urban system (overall urban system) exists in the Greater PRD area: the values of the Central Place Importance (CPI), the complementarity relationships, the rank-size distribution, co-operation/integration between cities, and the densely distributed modern infrastructure system (highways, railways, airports, harbors, etc.). The values of the CPI indicate that there is an urban system of differently sized settlements that are geographically distributed across the study area. Moreover, a hierarchy exists between these urban centers. The complementarity analysis shows that interactions are present and are even stronger than the typical "polycentric urban system" of the Randstad. The rank-size distribution graph of the top 13 metropolises shows that the relative sizes of the different cities are becoming more equal, although the slope of the regression line is still somewhat steep. Further, it is not difficult to find that the Greater PRD was, is, and will be gradually developing close regional co-operation and co-ordination. All of these factors, combined with the modern infrastructure system, reveal that the prerequisites for forming a regional network urban system are present and that a network urban system in fact exists. Figure 6 shows the framework of this network.

\section{Conclusions}

Since CPT has deficiencies in describing regional urban systems especially those

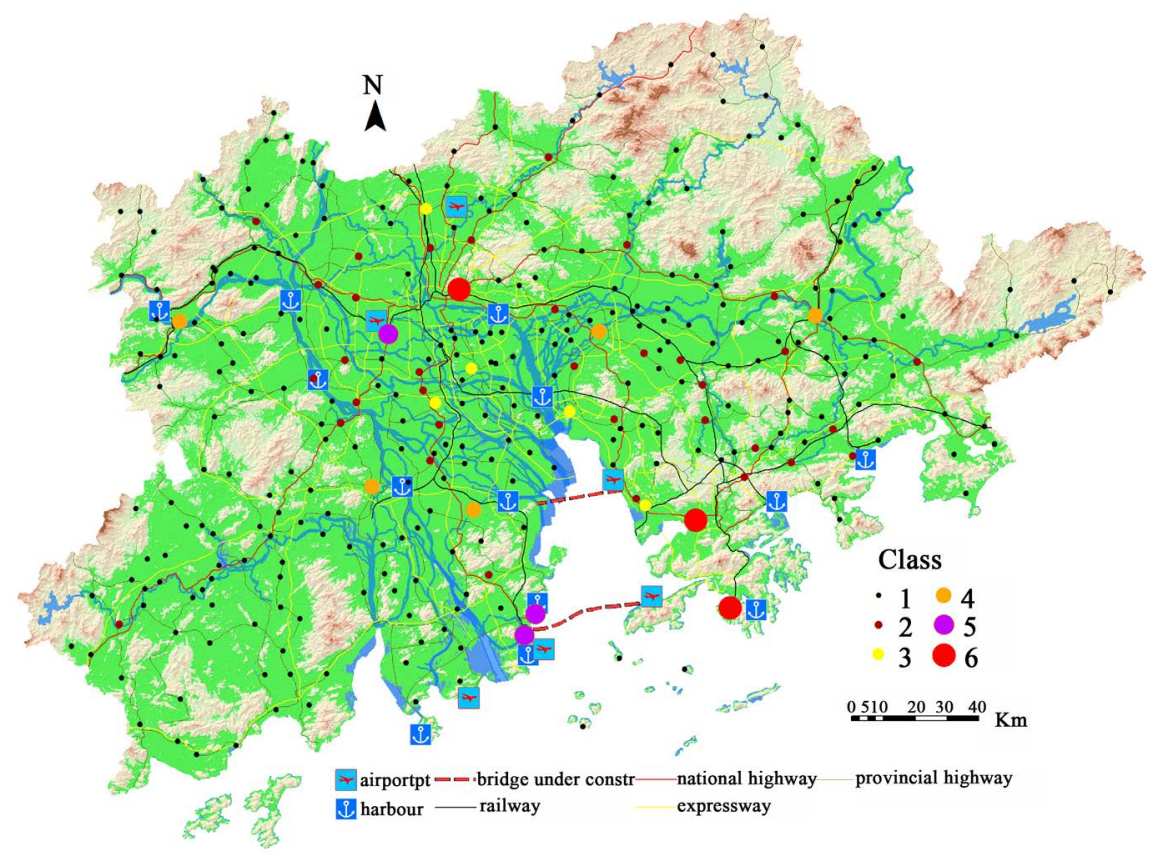

Figure 6. Network urban system of the Greater PRD study area. 
dimensions contributing to urbanization but not regulated by centrality, and polycentric urban region theory also encounters obstacles in defining the relative importance of settlements, researchers have being trying to solve these dilemmas. But to our knowledge, there still have no systematic analysis in integrating these two theories on forming the modern urban systems.

This paper has addressed two main questions: is it feasible to build a theoretical framework for a regional overall urban system based on central place theory and urban network idea? And, is there currently a network urban system within the Greater PRD? And through the works schemed above, there seems arise somewhat possibility, even feasibility that the assumed proposition holds. Also it has been proved that there exists a regional urban network within the study area.

We believe that our contributions on urban system studies are the integration of CPT and network city theory, and the empirical testing by employing the Greater PRD as a case study area. Continuous studies on detailed discussions and more profound insights are needed.

\section{Conflicts of Interest}

The authors declare no conflicts of interest regarding the publication of this paper.

\section{References}

[1] Alonso, W. (1973) Urban Zero Population Growth. Daedalus, 109, 191-206.

[2] Meijers, E. (2007) From Central Place to Network Model: Theory and Evidence of a Paradigm Change. Tijdschrift Voor Economische en Sociale Geografie, 98, 245-259. https://doi.org/10.1111/j.1467-9663.2007.00394.x

[3] Christaller, W. (1933) Die Zentralen Orte in Süddeutschland. In: Baskin, C.W., Trans., Central Places in Southern Germany.

[4] Lösch, A. (1941) Die Raumliche Ordnung der Wirtshcaft. In: Woglom, W.H. and Stolper, W.P., Trans., The Economics of Location, Yale University, New Haven.

[5] Brown, S. (1995) Christaller Knew My Father: Recycling Central Place Theory. Journal of Macromarketing, 15, 60-72. https://doi.org/10.1177/027614679501500107

[6] Meijers, E. (2007) Clones or Complements? The Division of Labour between the Main Cities of the Randstad, the Flemish Diamond and the Rheinruhr Area. Regional Studies, 41, 889-900. https://doi.org/10.1080/00343400601120239

[7] Parr, J. (2002) The Location of Economic Activity: Central Place Theory and the Wider Urban System. In: McCann, P., Ed., Industrial Location Economics, Edward Elgar Publishing House, Cheltenham, 32-82. https://doi.org/10.4337/9781781950746.00010

[8] Burton, I. (1963) A Restatement of the Dispersed City Hypothesis. Annals of the Association of American Geographers, 53, 285-289. https://doi.org/10.1111/j.1467-8306.1963.tb00449.x

[9] Camagni, R. and Salone, C. (1993) Network Urban Structures in Northern Italy: Elements for a Theoretical Framework. Urban Studies, 30, 1053-1064. https://doi.org/10.1080/00420989320080941 
[10] Kloosterman, R. and Musterd, S. (2001) The Polycentric Urban Region: Towards a Research Agenda. Urban Studies, 38, 623-633. https://doi.org/10.1080/00420980120035259

[11] Batten, D. (1995) Network Cities: Creative Urban Agglomerations for the 21st century. Urban Studies, 32, 313-327. https://doi.org/10.1080/00420989550013103

[12] Preston, R.E. (1971) The Structure of Central Place Systems. Economic Geography, 47, 136-155. https://doi.org/10.2307/143042

[13] Davies, W. (1967) Centrality and the Central Place Hierarchy. Urban Studies, 4, 61-79. https://doi.org/10.1080/00420986720080041

[14] Berry, B.J.L. and Garrison, W.L. (1958) Recent Developments of Central Place Theory. Papers of in Regional Science, 4, 107-120. https://doi.org/10.1111/j.1435-5597.1958.tb01625.x

[15] Clark, P.J. (1956) Grouping in Spatial Distributions. Science, 123, 373-374. https://doi.org/10.1126/science.123.3192.373

[16] Meijers, E. (2005) Polycentric Urban Regions and the Quest for Synergy: Is a Network of Cities More than the Sum of the Parts? Urban Studies, 42, 765-781. https://doi.org/10.1080/00420980500060384 